\title{
LIMITATION OF IMPLANTATION OF ENDOVASCULAR STENT-GRAFT: CASE REPORT OF A PATIENT WITH THORACOABDOMINAL ANEURYSM
}

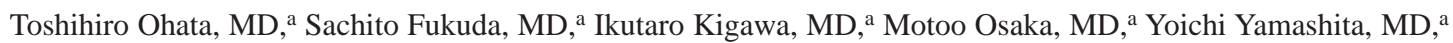
Yasuhiko Wanibuchi, MD, ${ }^{\mathrm{a}}$ and Masaaki Kato, MD, ${ }^{\mathrm{b}}$ Tokyo, Japan

Recently the transluminal placement of endovascular stentgraft prostheses has offered a largely successful alternative approach to the treatment of thoracic aortic aneurysm, an approach that is less invasive and carries a lower risk than does the standard operative method. ${ }^{1,2}$ However, cardiac surgeons who use the new method have not fully determined optimum indications for applying this alternative to open repair. We report on the autopsy of a patient with reruptured thoracoabdominal aneurysm after endovascular stent-grafting 6 months previously.

Clinical summary. A 76-year-old man was admitted to our hospital with a diagnosis of thoracoabdominal aneurysm. He had undergone distal gastrectomy, a low anterior resection for early-stage gastric and sigmoid colon cancer, and radical neck resection for a soft-palate cancer. His height was $152 \mathrm{~cm}$ and his body weight was $39 \mathrm{~kg}$. He had significant psychroesthesia in all 4 limbs and anterior chest pain. A large thoracoabdominal aneurysm, $10.0 \times 6.7 \mathrm{~cm}$ in diameter, extended to just above the celiac artery. For the prevention of impending rupture, we decided that implantation of an endovascular stent-graft, rather than the usual thoracotomy and graft replacement, was indicated because of the patient's poor general conditions.

The dimensions of the stent-graft were determined by his preoperative computed tomographic and angiographic evaluations. The stent-graft, covered by $32 \times 190-\mathrm{mm}$ thin-walled woven polyester, was $34 \mathrm{~mm}$ in diameter and $200 \mathrm{~mm}$ long. Spinal fluid was drained through a catheter placed in the lumbar space before the operation to ensure spinal cord protection. The endovascular stent-graft was implanted into the descending thoracic aorta from the right femoral artery. Although we attempted to place and fix the distal edge of the stent-graft just above the celiac artery, it moved to the cranial side of the aorta. Because of perigraft leakage seen at the distal edge of the stent-graft on intraoperative angiogram, a second implantation was attempted. The second stent-graft, $35 \times$

From the Division of Cardiovascular Surgery, Mitsui Memorial Hospital, Tokyo, ${ }^{\text {a }}$ Division of Cardiovascular Surgery, Osaka Prefectural Hospital, Osaka.

Received for publication May 20, 1998; accepted for publication June 22, 1998.

Address for reprints: Toshihiro Ohata, MD, Division of Cardiovascular Surgery, Mitsui Memorial Hospital, 1, Kanda Izumi-cho, Chiyoda-ku, Tokyo 101-8643, Japan.

J Thorac Cardiovasc Surg 1998;116:876-7

Copyright $\odot 1998$ by Mosby, Inc.

0022-5223/98 \$5.00+ $0 \quad \mathbf{1 2 / 5 4 / 9 2 6 1 1}$

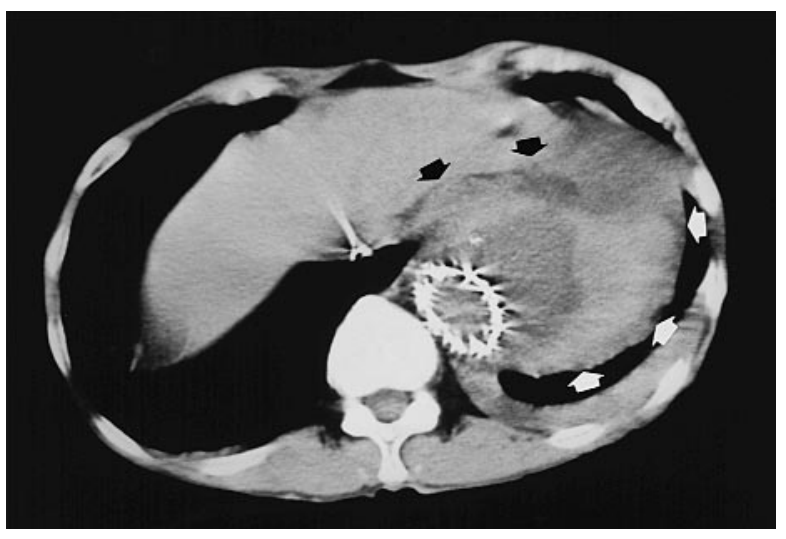

Fig 1. Computed tomographic findings of the impending rupture of the residual aneurysm around the stent-graft. A lowdensity mass around the lower stent-graft was seen on plain computed tomographic scan. Arrows show hematoma around the stent-graft.

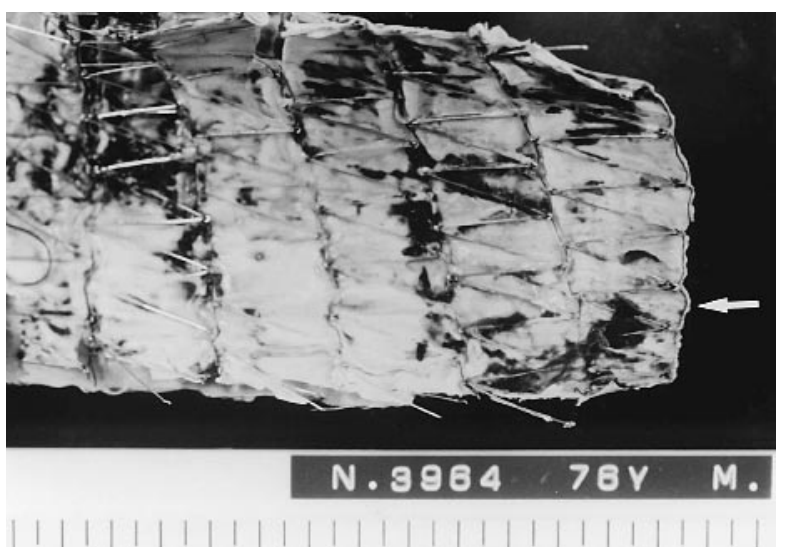

Fig 2. Photograph of the stent-graft. A crease in the graft jacket and a gap between the stent and the aorta were observed at the distal edge of the stent. Arrows show a crease of the stent jacket.

$140 \mathrm{~mm}$, was covered with $30 \times 100$-mm thin-walled woven polyester. Postoperative aortography and computed tomographic scanning demonstrated neither further nor recurrent perigraft leakage. The patient was discharged despite restriction of movement and dysuria associated with a neurogenic bladder. 
Six months after stent-graft implantation, the patient had sudden right back pain and was transferred by ambulance in shock. Impending rupture of the aneurysm at the distal edge of the stent-graft was suspected on the basis of emergency chest and abdominal computed tomographic studies (Fig 1). We instituted medical therapy because his poor general conditions would not permit additional surgical intervention. An autopsy disclosed no tear in the stent-graft but did show a crease in the graft jacket and a gap between the stent-graft and the aorta at the distal edge of the stent (Fig 2). The cause of rupture was suspected to be the reversed blood flow through this space. The inner surface of the graft was intact, and epithelialization with native endothelium over the metallic stent had not taken place.

Discussion. Dotter and associates ${ }^{3}$ initially proposed the concept of a transluminally placed endovascular graft in 1969. Since then some reports on the clinical use of balloonexpandable or self-expanding stent-grafts have been presented. ${ }^{1,2,4}$ Although authors of these articles reported the utility of this procedure, they also discussed its problems and complications, such as the need for a second procedure, transient chest pain, pleural effusion, and perigraft leakage. ${ }^{1,2,4}$ This is the first report concerning the rupture of the residual aneurysm induced by perigraft leakage. In this case, it was suggested that preventing re-enlargement or rupture of the residual aneurysm at the distal edge of the stent-graft would be difficult. These problems indeed may constitute a limitation of the current procedure for implantation of an endovascular stent-graft. Additionally, fixation of the distal edge of the stent-graft to the aortic wall is difficult in cases of extremely large thoracoabdominal aneurysm located immediately above the celiac artery.
Several other approaches may be applicable in a case such as ours. Inoue and colleagues ${ }^{5}$ reported transluminal endovascular placement of a branched graft with a side arm extending into the left subclavian artery and celiac axis in a type B dissecting aneurysm. Other approaches include placement of a third stent implant, coil embolization at the rupture, or closure with another stent, followed by extra-anatomic bypass grafting to major arteries.

Clearly, problems of graft fixation in cases of large thoracoabdominal aneurysm and reinforcement of the graft jacket need to be resolved. Transluminal endovascular stent-grafting can thus become a still safer alternative treatment for the patient whose condition is too poor for graft replacement through a thoracotomy.

\section{REFERENCES}

1. Parodi JC, Palmaz JC, Barone HD. Transfemoral intraluminal graft implantation for abdominal aortic aneurysms. Ann Vasc Surg 1991;5:491-9.

2. Dake MD, Miller DC, Semba CP, Mitchell RS, Walker PJ, Liddel RP. Transluminal placement of endovascular stent-grafts for the treatment of descending thoracic aortic aneurysms. N Engl J Med 1994;331:1729-34.

3. Dotter CT. Transluminally-placed coilspring endarterial tube grafts. Longterm patency in canine popliteal artery. Invest Radiol 1969;4:329-32.

4. Kato M, Matsuda T, Kaneko M, Ueda T, Kuratani T, Yoshioka Y, et al. Experimental assessment of newly devised transcatheter stent-graft for aortic dissection. Ann Thorac Surg 1995;59:908-15.

5. Inoue K, Iwase T, Sato M, Yoshida Y, Ueno K, Tamaki S, et al. Transluminal endovascular branched graft placement for pseudoaneurysm: reconstruction of the descending thoracic aorta including the celiac axis. J Thorac Cardiovasc Surg 1997;114: $859-61$. 